\title{
Leer en el destierro. Escenas de lectura en los periódicos de fray Castañeda ${ }^{*}$
}

\author{
Reading in Exile: Reading Scenes in the Newspapers \\ of Friar Castañeda
}

María Laura Romano**

\section{RESUMEN}

En 1821, el cura porteño Francisco de Paula Castañeda fue desPalabras clave: terrado de Buenos Aires a causa de la irreverencia de sus publisiglo XIX, caciones periódicas. En el número 73 del Despertador Teofilanhistoria de la trópico Místico-Político, que salió a la luz una vez que el fraile ya lectura, literatura estaba de regreso en la ciudad, se publicó un extenso texto en el que Castañeda relata cómo fue su exilio. El artículo analiza las distintas escenas de lectura que componen esa narración y sus vínculos con otras representaciones de la práctica lectora aparecidas en publicaciones del autor. Se trata, en todos los casos, argentina, prensa argentina, Francisco de Paula Castañeda. de figuraciones en las que la lectura se desenvuelve en contextos de carencias materiales y simbólicas y que construyen un perfil de Castañeda no solo como redactor de periódicos, sino también como lector de libros.
ABSTRACT
In 1821, priest Francisco de Paula Castañeda was exiled from Keywords: 19th Buenos Aires due to the irreverence of his newspapers. In the 73rd edition of Despertador Teofilantrópico Místico-Político, which came to light once the friar was already back in Buenos century, history of reading, Argentinian Aires, Castañeda published an extensive text about his exile. This
literature,

Este artículo se desprende de mi proyecto doctoral finalizado en 2018 con la defensa de la tesis "Monstruos de la razón. Periódicos no ilustrados en la región platina (1820-1830)". A su vez, dialoga con las investigaciones llevadas a cabo en el marco del proyecto UBACyT (20020190200286BA) "Dimensiones gráficas, materiales y espaciales en la cultura literaria y visual del Cono Sur, 1810-1960", dirigido por las doctoras Adriana Amante e Inés de Mendonça.

"* Argentina. Doctora de la Universidad de Buenos Aires, área Literatura. Becaria posdoctoral del Consejo Nacional de Investigaciones Científicas y Técnicas, Buenos Aires, Argentina.malauromano@gmail.com 
article analyzes the different reading scenes that compose this narrative and their link to other representations of reading practices that appear in the author's publications. In all cases, they are figures in which reading takes place in contexts of material and symbolic deficiency, drawing a picture of Castañeda not only as a newspaper writer but also as a book reader.
Argentinian press,

Francisco de Paula

Castañeda 


\section{Un desierto sin libros}

Como continuidad casi natural de la preponderancia que tuvieron los religiosos en la vida intelectual de los centros urbanos coloniales durante la crisis de las monarquías ibéricas, muchos sacerdotes desempeñaron funciones importantes en las incipientes esferas públicas de las capitales sudamericanas, entre las que destacó su participación en la prensa. Al respecto, menciono solo tres figuras relevantes de las múltiples que se podrían citar, figuras de trayectoria disímiles pero que coinciden en haber hecho un uso más o menos intensivo del nuevo dispositivo de comunicación. En Pernambuco, el cura Joaquim da Silva Rabelo (1779-1825), más conocido como frei Caneca, aprovechó el periódico para la difusión de los principios liberales y se convirtió en uno de los referentes indiscutidos de la prensa de oposición al poder colonial. Otro tanto hizo el sacerdote mexicano José María Luis Mora (1794-1850), masón como Caneca, que escribió para varios periódicos de su país y fundó dos órganos de prensa liberales; por su parte, la $G a$ zeta de Buenos Ayres, importante órgano oficial del primer gobierno patrio de aquella ciudad estuvo a cargo de un prominente eclesiástico porteño, el deán Gregorio Funes (1749-1829), en el álgido año de 1811.

Durante la segunda década del siglo XIX, Francisco de Paula Castañeda fue uno de los religiosos que se dedicó con más ahínco a la escritura periodística en Buenos Aires. Entre 1820 y 1822, sus incendiarios papeles causaron revuelo y malestar entre los sectores ilustrados cercanos al por entonces ministro Bernardino Rivadavia. Su conservadurismo y su agria crítica a las sucesivas administraciones porteñas expusieron al cura a una serie de castigos entre los que se cuentan dos condenas al destierro, la segunda de las cuales significó su partida definitiva de la ciudad. El primer destierro tuvo lugar en 1821. En esa ocasión, se le prohibió escribir para el público (a la sazón era redactor de siete periódicos simultáneos) ${ }^{1}$ y se lo expulsó a un lugar desolado de la pampa bonaerense, Kaquel Huincul, en donde debía permanecer por

Listo los periódicos por orden de aparición: Despertador Teofilantrópico MísticoPolítico; Suplemento al Despertador Teofilantrópico Místico-Político; Paralipómenon al Suplemento del Teofilantrópico; Desengañador Gauchi-Político [...]; Doña María Retazos; y Dom Eu Nam Me Meto com Ninguem. Para una caracterización global del ingente proyecto de prensa de Castañeda, véanse los trabajos de Claudia Roman (2010, 2014a, 2014b) y Virginia Forace $(2016,2017)$. 
cuatro años ${ }^{2}$. Gracias a una conmutación de la pena otorgada por el gobernador Martín Rodríguez, pasó solo un año antes de que el fraile pudiese reanudar sus publicaciones. Ni bien regresó a Buenos Aires, Castañeda retomó el Despertador Teofilantrópico Místico-Político ${ }^{3}$, su primer periódico, siguiendo la numeración allí donde se había interrumpido. El número 73, del 13 de septiembre de 1822, está ocupado casi completamente por un texto en el que el personaje enunciador del periódico relata la triste partida de la ciudad junto con su compañero el Suplementista, otro de los papeles del fraile que funcionaba, como su título sugiere, a manera de suplemento del Despertador ${ }^{4}$. Se trata de una narración interesante porque refleja los sinuosos posicionamientos de Castañeda en torno a los libros, la lectura, el saber, la tradición, la historia y su relación con la experiencia. El propósito de mi artículo es indagar en esos aspectos de la prosa del cura usando el relato mencionado como hilo vertebrador; asimismo, en él podrían enhebrarse otros fragmentos de sus periódicos que, relativos al universo libresco, permiten componer una imagen de Castañeda no ya como redactor de periódicos, sino como lector de libros.

En efecto, entre los papeles que Castañeda hizo circular en Buenos Aires, hay diversas referencias y reflexiones acerca del libro y sus lugares de conservación y ordenamiento: las bibliotecas. En una operación que puede comprenderse con el concepto de re-mediation ("la representación de un medio en otro medio”, según palabras de David Bolter y Richard Grusin 45), el fraile usó de manera recurrente el no-

\footnotetext{
2 Adolfo Saldías, en su biografía de Castañeda, relata este primer destierro e informa cuáles fueron sus causas (193-200). El segundo destierro se produjo a principios de 1823 por orden de la Junta de Representantes que consideró subversivos sus periódicos La Guardia Vendida por el Centinela y La Verdad Desnuda. En esta ocasión, Castañeda huyó a Montevideo y después se trasladó a Santa Fe, donde permanecería hasta el día de su muerte en 1832.

3 Circuló en Buenos Aires entre abril de 1820 y octubre de 1822. La colección consta de 75 números (Zinny 283). El número 1, que funcionó a la manera de prospecto, incluyó una extensa dedicatoria "a las matronas argentinas y por medio de ellas á todas las personas de su sexo que pueblan hoy la faz de la tierra y la poblarán en la sucesión de los siglos". A lo largo del texto, me refiero a este periódico como Despertador.

$4 \quad$ Los 21 números del Suplemento al Despertador Teofilantrópico Místico-Político se publicaron entre 1820 y 1822 (Zinny 251). La prensa de Castañeda se caracterizó por la construcción de personajes en los que encarnaba la voz enunciadora de los periódicos (el Despertador, el Suplementista, el Gauchipolítico, Doña María Retazos, D. Eu, etc.). Uso letra cursiva cuando me refiero a los periódicos y letra redonda para referirme a los personajes, aunque hay que aclarar que esa distinción a veces puede resultar difusa.
} 
vedoso dispositivo de comunicación para referirse a una tecnología de la palabra impresa más antigua, cuyas prerrogativas el periódico supuestamente había venido a desbancar. Enfatiza, por ejemplo, las virtudes de las bibliotecas de las órdenes religiosas, que conservaron la literatura clásica "mientras todo el mundo era bárbaro" ${ }^{5}$; recomienda libros pertenecientes a las bibliotecas del Convento de la Recolección al que pertenecía (Despertador 39), (Doña María Retazos 149); se queja porque la biblioteca pública permanece cerrada la mayor parte del día (Despertador 1052) o porque sus estantes están llenos de libros robados a los conventos (Doña María Retazos 149).

De ese tipo de representaciones, que pueden asociarse con aquellas trabajadas por diversos estudios acerca de la lectura en el ámbito rioplatense decimonónico (Parada, 1998, 2012; Batticuore, 2005, 2008; Brunetti, Maggio Ramírezy Grillo, 2008; Martínez Gramuglia, 2012; Pas, $2017,2018)^{6}$, mi análisis propone un sesgo particular puesto que destaca - y con eso se vincula el relato central que analizo- la relación que construye el fraile con los libros cuando ellos están en falta, son escasos o son inútiles porque ya no colman las expectativas del lector. Es que en el revés del lamento por la carencia o escasez de materiales impresos surgen algunas imágenes interesantes que funcionan como huella de las prácticas de lectura y escritura en las que Castañeda estaba comprometido: "Me abanzo a escribir en un desierto sin libros, y sin todos esos auxilios que son comunes en los pueblos grandes", afirma el cura en el prospecto de Vete portuguez, que aquí no es (1828). Para entonces, Castañeda estaba instalado en Santa Fe, ciudad que lo había acogido luego de su segunda expulsión de Buenos Aires. En ese enunciado, donde otra vez aparece cifrada la pérdida material y simbólica que el exilio suponía para él, reverberan por lo menos dos sentidos que

En todas las citas de los periódicos conservé la ortografía, la puntuación y las marcas de énfasis originales. Dado que las publicaciones citadas tienen paginación corrida, indico entre paréntesis el número de página original, a excepción de Doña María Reta$z o s$, caso en el que coloqué la numeración de la edición facsimilar, y Vete portuguez, que aqui no es, que no está paginado.

$6 \quad$ Se trata de estudios de distinto nivel de exhaustividad que permiten reconstruir los sentidos asociados al acto de leer en la primera mitad del siglo XIX a partir del énfasis en objetos diversos: el lector de periódicos (Martínez Gramuglia; Pas; Brunetti, Maggio Ramírez y Grillo), la lectora mujer (Batticuore), la lectura relacionada con los espacios bibliotecarios (Parada) y la influencia de los textos instruccionales en las representaciones de la lectura (Maggio Ramírez). 
articulan su perfil como periodista y predicador. En primer lugar, emerge un significado ligado a lo dificultoso que resultaba escribir sin poder consultar libros, lo que viene a revelar, como corolario, su método de trabajo: el cura escribía leyendo. En segundo lugar, ese "desierto sin libros" mentaba el espacio social y material desde el cual escribía, la ciudad de Santa Fe, probablemente escasa en libros, bibliotecas, periódicos y lectores (todo ello por lo menos en relación con Buenos Aires, el "pueblo grande" en el que, entre otros quizá más grandes, Castañeda seguramente pensó). El lamento del fraile acerca de los despojos sufridos constituye un lugar común del discurso de los desterrados americanos por lo menos desde fines del siglo XVIII (piénsese fundamentalmente en la literatura de la diáspora jesuítica). "A mí me es imposible dejar borrador de mis escritos" confiesa también en el prospecto de Vete Portuguez al quejarse por el extravío de tres números de su publicación Los Derechos del Hombre (¿no es una queja también por no poder construir su archivo de escritor?). La vida itinerante y de escasez obligaba a leer y a escribir casi en el borde de la imposibilidad.

No obstante, además, en estas imágenes relacionadas con la falta resuena un lugar común de origen bíblico: "predicar en el desierto". Castañeda había usado ese tópico para dar cuenta de su situación en Buenos Aires como voz disonante que nadie quería escuchar (Despertador 366). En la estela de sentido que irradiaba esa imagen, la ciudad porteña devenía un desierto, sino de libros, por lo menos de periódicos, más específicamente, un desierto de periódicos con voces concordantes con la ideología del cura. No está de más recordar que su primera publicación salió a la luz en 1820, en el contexto en el que comenzaba a discutirse la reforma eclesiástica. Acicateado por la aciaga coyuntura, el fraile se esforzó por "devenir varios" periódicos a la vez, como si hubiese asumido la tarea de escribir todas las virtualidades de la prensa o, mejor, de escribir por aquellos (religiosos sobre todo) que habían decidido callar7. Algún éxito tuvo en esta empresa: en 1820 salieron en Buenos Aires 12 periódicos, de los cuales cuatro fueron

Son repetidas las quejas de Castañeda porque los curas no asumen la tarea a la que los obliga su ministerio: corregir a sus hijos. Cuando arreciaban las críticas contra él debido a su estilo insidioso, el fraile escribe: "yo confieso mi culpa de que no he dicho ni la mitad, ni la cuarta parte de todo lo que pudiera haber dicho" (Despertador 888-889). 
creación del cura; de las diez publicaciones aparecidas el año siguiente, siete eran redactadas por él. Pocos contemporáneos fueron indiferentes a esta gran masa de escritos públicos. La sátira virulenta se entrelazaba en ellos con diferentes modalidades de la polémica, de lo que resultaba un discurso explosivo ${ }^{8}$. Así la prensa de Castañeda, ubicada a contramano de los ejes directrices de la intelectualidad rivadaviana, creció nutriendo y nutriéndose de un contexto hostil, desierto a la medida de un cura dispuesto a desafiar toda autoridad que no fuese la de Dios. Lo notable es que ese desierto se haya convertido en un lugar real de enunciación cuando el fraile fue obligado a trasladarse a un paraje desolado de la

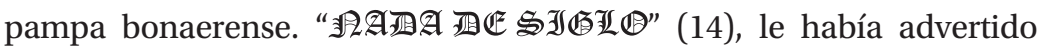
Pedro Feliciano Sáenz de Cavia, uno de sus principales contrincantes, algunos meses antes de su primer destierro. Publicado en el papel que este redactaba contra Castañeda, Cuatro Cosas o el Antifanático, el enunciado estaba impreso en irónicos caracteres góticos. De esa manera, el mensaje amenazante redundaba en la anacrónica letra descubriendo la intencionalidad última de la pena: Cavia era consciente de que, para un grafómano como el fraile, la expulsión de la ciudad significaba sobre todo quedar privado de las tecnologías que, a lo largo de los últimos siglos, habían permitido una mejor conservación, acceso y difusión de la palabra escrita9 ${ }^{9}$.

\section{El libro de los libros}

El número 73 del Despertador es clave para comprender el exilio de Castañeda como un alejamiento forzado de los libros, las bibliotecas, las imprentas y de todo lo que se asociaba con su quehacer letrado. Colocando como protagonistas a dos de sus personajes-periódico, el Despertador y el Suplementista, el fraile narra en voz del primero las

\footnotetext{
8 Castañeda entabló fuertes polémicas con El Año Veinte, La Gaceta de Buenos Aires, El Argos de Buenos Aires y El Lobera del Año Veinte. Los periódicos de Cavia merecen una mención aparte, puesto que junto con su redactor, fueron uno de los blancos preferidos del cura. Me refiero a El Imparcial (1820-1821) y a Cuatro Cosas o el Antifanático: el Amigo de la Ilustración, cuya Hija Primogénita es la Tolerancia: el Glosador de los Papeles Públicos Internos y Externos; y el Defensor del Crédito de Buenos Aires y Demás Provincias Hermanas.

9 Ya nos referimos a Cuatro Cosas o el Antifanático en la nota anterior. El texto completo de amenaza es el siguiente: "[...] y sepa finalmente que Cuatro cosas le pronostica que ha de tener al fin y al postre un martirio... pero ¡qué martirio! ¿Quiere saberlo? Pues

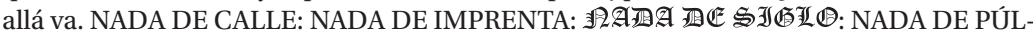
PITO; CUATRO COSAS" (14).
} 
tristes circunstancias de la partida de Buenos Aires. Ante la inminencia del destierro, las criaturas de papel que animan el relato apuestan por la lectura como una práctica de potencial carácter terapéutico. Sin embargo, en principio, ese remedio contra la amargura que suscitaba la expulsión muestra sus limitaciones:

La historia de lo pasado es en cualquier tribulación un documento que llena de esperanza y de consuelo á los atribulados: el Suplementista y yo recorrimos una por una las historias para encontrar alivio en nuestro quebranto pero todas las historias nos parecían mancas y caducas, ó fuese porque nosotros eramos los que caducábamos, ó porque no hay historia que sea puntual, ó porque nunca lo pasado es tan vivo como lo presente. (1063-1064)

El recorrido infructuoso por las historias del pasado replicaba la condición del exilio: los personajes de Castañeda eran desterrados también del recinto de sabiduría que construían los libros. Esta situación escenifica la fractura de un modo tradicional de pensar la historia como magistrae vitae. En la concepción del tiempo histórico propia de la cultura eclesiástica de la época, el devenir humano no se concebía como una línea recta constituida por hechos únicos e irrepetibles, sino como un "juego de reflejos especulares" que entrelazaban el presente con el más antiguo pasado y aportaban un sentido para el porvenir en el marco de una concepción en la que la Causa Primera de todas las cosas era Dios (Di Stefano 206). Buscar, rebuscar y no hallar ningún exemplum que conviniera a su situación hacía añicos la estructura de saberes que Castañeda había desplegado en sus periódicos y que justificaba su empresa como escritor público. En el número 36, el Despertador había prometido "recurrir ya à la historia natural, ya à la favula, ya à los fastos, y anàles de todos los siglos para sacar pasages que abochornen à los que ni aun perdonados escarmientan" (468). La literatura didáctica (apólogos, parábolas y fábulas) de la que frecuentemente se valía el cura para cumplir el objetivo de instrucción que había dado a sus papeles portaba un sentido ideológico muy preciso. Los "pasages al caso" que el fraile escribía en las páginas de sus hojas y de los que extraía siempre una "moralidad" subsumían un hecho particular de su presente en el acervo de experiencias ejemplares de las que emanaban valores ligados a la sociedad tradicional. Más allá de las adaptaciones al contexto local de las que eran objeto sus relatos, la forma en sí de la 
fábula o el apólogo movilizaba una sabiduría que venía del fondo del tiempo y cuyo valor era, por definición, eternamente actualizable ${ }^{10}$.

Pero la actitud expectante del Despertador y de su compañero respecto de las historias pasadas tenía que ver puntualmente con poner al servicio de las penurias de los hombres y las mujeres del siglo XIX la sabiduría atesorada en los libros. Desgracias, tristezas, penas extraordinarias que había que aprender a aliviar para hacer más llevadero el mundo. Cincuenta años después, el gaucho Martín Fierro se consolaría con el canto acompañado de una vihuela. Los personajes de Castañeda, criaturas de estirpe letrada, que no tenían vida más allá del papel y la letra en la que inscribían su biografía, no podían aliviar sus tribulaciones más que leyendo. Fuera de esta diferencia, lo que interesa es que el aparato de saberes, en uno y otro texto, (dis)funcionaba bajo el mismo principio. Julio Schvarztman recuerda la idea de Ezequiel Martínez Estrada de que el decir sentencioso del poema de Hernández tendía un puente entre el suceso particular y la historia de los sufrimientos humanos. Este puente sería parte de la "operación reguladora y ordenadora" de la experiencia que realiza el saber proverbial. "Inscribir el sufrimiento individual en un largo proceso histórico provee sentido pero también resignación", puntualiza Schvarztman (104). Era precisamente esa inscripción la que fallaba en el trance que atravesaban los personajes de Castañeda, el que por otra parte configuraba una escena de partida forzosa en la que, retrospectivamente, resuena el exilio de Fierro y Cruz y la camaradería de los compañeros que caen juntos en desgracia.

Debido a la naturaleza irrepetible de un acontecimiento que no encajaba en ninguna de las historias conocidas, la soledad y el desamparo de los personajes se amplificaban. El sentimiento de radical historicidad del que daba cuenta el Despertador ("pero todas las historias nos parecían mancas y caducas, ó fuese porque nosotros eramos los que caducábamos, ó porque no hay historia que sea puntual,

10 El uso de la literatura didáctica vincula a Castañeda, por un lado, con el moralismo cristiano de la literatura del Barroco (la tradición de los desengaños y despertadores, en la que se incluye Castañeda y muchos otros periodistas del siglo XIX, tenía sus raíces en textos clásicos del 1600 como los Sueños de Quevedo y El diablo Cojuelo de Vélez de Guevara). Por otro lado, el empleo de esas formas pedagógicas enlazaban el proyecto del fraile con el discurso reformista ilustrado. 
ó porque nunca lo pasado es tan vivo como lo presente"), reenviaba a una nueva condición de los saberes y de la tecnología empleada para su transmisión, la escritura impresa, que despuntaba en un escenario social en el que avanzaba la modernidad con sus influjos secularizantes. ¿Dónde buscarían el Despertador y el Suplementista las historias en las que descansar sus penas? Se puede imaginar que en libros, en "el libro de los libros", la Biblia, en el Nuevo Testamento, que funcionó para los cristianos al modo de un vade-mécum (palabra latina que significaba literalmente "ven conmigo"), de un compañero de vida. La búsqueda infructuosa de los personajes coincidía con la aparición y multiplicación del libro más perecedero de todos, el periódico, que Castañeda había elegido como plataforma para disparar sus dardos censorios contra los corifeos del siglo XIX. La emergencia del nuevo medio modificó los lugares en los que se depositaban y podían encontrarse los saberes e insufló a estos un valor temporal, una duración: en sus páginas, ningún escrito, cualquiera fuera la índole del conocimiento que transmitiese, permanecía indemne al paso del tiempo.

Ahora bien, en el recorrido una por una de las historias del pasado que hicieron el Despertador y el Suplementista, algo del funcionamiento del saber tradicional terminaba restableciéndose. Finalmente, aparecía la "historia puntualísima", la "historia verdadera": El ingenioso hidalgo don Quijote de la Mancha. Así, luego de la búsqueda infructuosa en "las historias", se configuraba la segunda escena de lectura que contenía el relato: el Suplementista "tomó en sus manos el precioso libro, y puestas las antiparras, y dando de narices en el capitulo 47 de la segunda parte leyó en voz alta el párrafo siguiente" (1064). Se trata del capítulo en el que don Quijote y Sancho Panza deciden volverse pastores para cumplir con la prohibición de usar las armas que pesaba sobre el manchego. La espada del personaje de Cervantes quedaba asimilada así a la pluma del fraile escritor. Un texto literario profano pasaba a ocupar el lugar de objeto de una lectura instructiva destinada a modelar las conductas. El Quijote devenía “una ley inviolable", según palabras del Suplementista, ya que les señalaba a los personajes un camino a seguir. Castañeda, que tanto lamentaba el alejamiento de Dios de la vida de los hombres y las mujeres decimonónicos, parecía alejarse él mismo de las lecturas piadosas. Pero, en realidad, lo hacía solo parcialmente, porque el modo de apropiación de la novela de Cervantes no 
renunciaba a otorgarle al texto cierta investidura religiosa basada en la relación pedagógica y de acatamiento de autoridad que los personajes establecían con el clásico español.

\section{El atadito y la leyenda}

En varias escenas del relato del Despertador gravita una tendencia sacralizante respecto de los libros y la lectura. En la elección que realiza el personaje de los volúmenes que lo acompañarán en su destierro, resuena por ejemplo una exhortación bíblica de la literatura proverbial: lleva la ley "siempre atada a tu corazón, y colgada como una joya a tu cuello" sentencia el libro de los Proverbios (La Biblia Latinoamérica, Prov. 6, 21). Así, el personaje cuenta que

en un atadito cargué la biblia: un librito de meditaciones de Fr. Luis de Granada: el sacerdote perfecto del P. Molina, y á Jamin pensamientos teológicos: por lo que hace á libros de política no cargué mas que á la insigne política, y admirable doctora Sor Teresa de Jesús (1066).

Como se ve, todos eran textos religiosos. ¿Qué sentidos de uso de los libros refulgen en esta imagen? En principio, el hecho de que el contenedor que sirve para transportar los volúmenes sea un "atadito" habla del tamaño pequeño de los objetos que acarrea; en efecto, el texto de Granada es identificado con el diminutivo "librito". Los tamaños y la forma física de los libros determinan los empleos a los que se los destina (Lyons 138-139; Martínez de Sousa 399-406). La cultura eclesiástica se caracterizó por estar muy atenta a esas cuestiones y por aprovechar de manera productiva los avances relativos a las tecnologías de la escritura. Por ejemplo, se cree que las primitivas comunidades cristianas fueron las primeras en preferir el códice al libro en rollo. Para Michel Melot, esta elección se explicaría porque el Evangelio era considerado un manual de vida que había que llevar siempre consigo; de ahí que hubiese sido necesario darlo a leer bajo una forma más manejable y transportable (30). Luego de la aparición de la imprenta, esa necesidad se reflejó en los formatos de reducidas dimensiones como si, de la era cristiana en adelante, el libro no hubiese hecho más que perfeccionar aquellas cualidades que lo tornaban un objeto escrito sumamente transportable. A diferencia de los libros de gran formato destinados para usos ceremoniales y monumentales, los pequeños vo- 
lúmenes se fabricaron históricamente para llevarse pegados al cuerpo, en un atadito cruzado en la espalda o sobre el hombro, como hacía el personaje de Castañeda, dentro de un bolsillo, colgados del cinto o del cuello como si se tratara de un amuleto.

Por otra parte, el "atadito de libros" en tanto objeto resulta sugerente. La palabra "atado" refiere a un conjunto de cosas liadas entre sí que en este caso, más que con un lío (un "lío de ropa", por ejemplo), se emparentaba con el ramo o el ramillete debido a su composición selecta. Esta última voz reenvía directamente al mundo de los géneros librescos. El florilegium, que literalmente significa "ramillete de flores", era una compilación de frases memorables de un mismo autor o de varios autores en torno a una temática. "Adagios, sentencias, anécdotas históricas o fábulas y toda frase aguda y breve o ingeniosa" eran recopilados en esa clase de volúmenes (López Poza 61). Las palabras latinas que identificaban las recopilaciones eran varias: además de florilegium, se usaban las voces thesauros, corpus, catalogus e, incluso, flores. En lengua vernácula también aparece en el mismo espectro semántico "biblioteca" (Chartier 72). Se trataba de géneros literarios que tenían la finalidad de hacer manejable la inmensa cantidad de textos que habían puesto en circulación el libro manuscrito y luego la imprenta. El atadito de libros que lleva el Despertador, si bien transporta textos enteros, es heredero de esas preocupaciones: su portabilidad aseguraba que el tesoro del saber - o por lo menos un fragmento selecto de él- estuviese disponible en cualquier lance en el que se estuviera.

Así como los florilegios se pueden asociar con los cuadernos de notas donde se coleccionaban pequeños retazos de textos (los codex excerptorius muy usados por los clérigos para elaborar sus sermones), el atadito de libros del Despertador construye la imagen de una biblioteca portátil y personal. Los libros juegan un rol protagónico en el relato de la partida de Buenos Aires y de la estancia de los periódicospersonajes en el pueblo bonaerense de las Conchas, lugar donde encontraron término a su errancia. Al ver los libros, la dueña de la casa que acogió a los desterrados pregunta: “ $¿$ son en castellano?". Signo de que la mujer no sabía leer, el interés por el idioma en el que estaban escritos subraya, además, el lazo cultural con la lengua y la literatura de la antigua metrópoli que Castañeda se empeñaba en reivindicar ante 
el avance de lo que llamaba despectivamente el espíritu "gaucho-britano-gálico" (Desengañador 28). Como agradecimiento a la hospitalidad que mostraba el pueblo, el Despertador decide compartir el saber atesorado en los libros que llevó consigo:

Diariamente de las once hasta las doce del dia, y desde las siete hasta las ocho de la noche se juntaban las vecinas en lo de nuestra patrona, y empezaba la leyenda teniendo yo cuidado de explicar, y comentar los lugares que me parecian de difícil inteligencia: solian también de cuando en cuando concurrir matronas del pueblo vecino, y ya la sociedad iba siendo numerosa (1069).

"Leyenda": palabra de gusto arcaico frente a la cual puede imaginarse el solaz del fraile como si se tratase de un bello objeto anticuado. La tercera escena de lectura que presenta el relato también es en voz alta, pero esta vez el destinatario es múltiple, una audiencia conformada exclusivamente por matronas que deviene "sociedad": sociedad teofilantrópica femenina, podría decirse, cuyas integrantes se recogen alrededor del Despertador y de los libros piadosos vocalizados por él. En ese espacio cuyos horarios marcaban la inminencia del punto más alto del sol y de su caída, los pequeños volúmenes transportados desde Buenos Aires en el frágil atadito proyectaban sus letras silenciosas más allá del recinto de la intimidad, gracias a la puesta en voz en una lectura comunitaria en torno de la cual se cimentaba una sociabilidad, en principio, más de índole instructiva que ociosa. El componente de instrucción se revelaba en las explicaciones y comentarios del cura acerca de los pasajes dificultosos de los libros, lo que vincula esta escena con los dispositivos de la oratoria sagrada, específicamente con la homilía, género que consiste en el comentario del texto bíblico para facilitar la comprensión ${ }^{11}$. Nótese, además, que el relato no registra la voz de ninguna de las mujeres que conformaban la apretada concurrencia. Sin embargo, ese silencio, que puede ser interpretado como signo de una actitud sumisa hacia

11 La catequesis, la homilía y el sermón son tres formas centrales de la predicación cristiana. En los dos primeros, prevalece el interés por lograr en los oyentes la comprensión de la fe cristiana y de los textos sagrados, respectivamente. Este objetivo determina que en ambos casos se prefiera el tono familiar. El sermón, que también puede consistir en la explicación de algún pasaje bíblico es, por el contrario, una forma de predicación de cierta solemnidad y formalidad (Herrejón Peredo 11). 
una figura de autoridad, también puede ser resultado de un estado de embelesamiento. Después de todo, las imágenes que propone la anfitriona para animar a su huésped son del registro de la atracción y de la glotonería: "yo le prometo á V. que las señoras concheras lo han de perseguir como moscas á la miel, y como las avejas á las flores; son muy amigas estas matronas de que les lean buenos libros" (Despertador 1068). Hay algo de la voracidad del deseo, entonces, por parte de las mujeres que escuchaban leer al Despertador; ahora bien, para poner a raya cualquier peligro de bibliomanía, Castañeda imaginó una práctica de lectura controlada y acotada (dos horas por día) que, además, estaba regulada por un varón anciano y piadoso.

No hay ninguna indicación de qué textos puntuales de su atadito les leía el Despertador a las concurrentes de esas reuniones. No obstante, el personaje enfatiza un rasgo de los libros que portaba: dice a la dueña de casa que la mayoría de ellos son de la mística española Santa Teresa de Jesús a quien, cuando enumera los impresos que cargaba, llama "insigne política". Castañeda en varias oportunidades se declaró admirador del misticismo. De hecho, apelando a un procedimiento característico de su profusa inventiva léxica, dejó huellas de su gusto por ese tipo de religiosidad en el nombre de su primer periódico. Al filantropismo propio de la prensa ilustrada y a las materias políticas que sin excepción abordaban las hojas que circulaban en la ciudad de Buenos Aires de la década de 1820, el cura les imprimió su singular sello calificando a su primogénito con el nombre de Despertador "teofilantrópico" "místico-político". Así, reescribió y torsionó el sentido de dos conceptos que se anudaban en la prensa decimonónica (filantropía y política) a través de un título que ponía la cuestión religiosa en primer lugar. Si la política era el campo del hacer del hombre que, en el malhadado siglo XIX, más se alejaba del Cielo para volverse terrenal y demasiado humana, el componente místico reenviaba a un horizonte de cercanía absoluta con Dios, a lo que Castañeda llamó en uno de los números iniciales del Despertador el "ilapso de la divinidad en la sustancia del alma" (145). Visto así podría pensarse que el cura construyó un perfil lector a imagen y semejanza de su biblioteca mística (las mujeres silenciosas y arrobadas que escuchaban al Despertador se parecían a sus santas) y que la escena de la leyenda en el pueblo de las Conchas era el grado cero de la comunidad deseada sobre el revés de una realidad desalentadora 
en la que los continuos enfrentamientos civiles de la década de $1820^{12}$ patentizaban las divisiones de la sociedad ${ }^{13}$.

\section{4. “¿Hasta cuándo ha de estar amancebado con los libros?"}

Es la pregunta que le hace al cura Doña María Retazos, su segunda criatura femenina. En el número 15 del periódico homónimo ${ }^{14}$, la joven matrona publica una carta enviada desde Kaquel Huincul en la que Castañeda - firmante del texto- se despachaba con todos los objetos que precisaba que le llevasen para cumplir con sus ministerios en tan desolado lugar. Entre botiquines y vacunas, el cura pide catecismos, catones, libros de meditaciones devotas y estampas de los misterios, "y todo en mucho número para dar, y repartir por toda esta inmensa campaña” (282). En la visión de la redactora, la necesidad de materiales impresos revela su verdadera naturaleza cuando el fraile le solicita la enciclopedia más completa de Buenos Aires:

¿No me dirá donde quiere colocar los cientos tantos tomos en folio de la Enciclopedia? ¿Ignora V.P. que en Kaquelhuincul mas se llueve dentro de las habitaciones que en el aire? Por eso es que su solicitud la atribuyo mas bien al vicio, ó á la costumbre inveterada de V.P. por los libros, que á un sano y maduro acuerdo. $(292)^{15}$

12 En 1820, las Provincias Unidas del Río de La Plata quedaron desmembradas tras la caída del gobierno central y la disolución del Congreso Nacional. Durante todo ese año y principios de 1821, el nuevo Estado provincial pugnó por nacer bajo los embates de la guerra facciosa. Se sucedieron gobiernos efímeros; las montoneras del interior ocuparon la provincia de Buenos Aires y hubo un profuso derramamiento de sangre (Ternavasio 119-130).

13 Así analizada, esta escena de lectura establece contrapuntos con las figuraciones de lo femenino en la prensa de Castañeda. En ella, las mujeres tienen un rol protagónico como corresponsales privilegiadas y editoras/redactoras. Su gran capacidad deliberante coagula en la Asamblea de las Matronas, espacio imaginario de quinientas mujeres reunidas para debatir sobre política con prescindencia de los hombres. La reunión de las mujeres de las Conchas recuerda la Asamblea (aunque, en el primer caso, se reunían alrededor de un varón).

14 Doña María Retazos salió entre el 27 de marzo de 1821 y el 1 de agosto de 1823. La colección consta de 16 números, el último de los cuales se imprimió en Montevideo, ciudad a la que Castañeda había escapado en ocasión de su segunda condena a destierro. Existe una edición facsimilar de este periódico, que es la que usé a lo largo del artículo.

15 A partir del análisis de los anuncios publicados en La Gaceta Mercantil, Alejandro Parada realizó un estudio de los libros que circulaban en Buenos Aires durante de época de Rivadavia. Respecto de las enciclopedias, indica que las que tenían una presencia reiterada en el periódico eran la Encyclopaedia Britannica, de 26 volúmenes; la Enciclo- 
El cura escribió las cartas a Doña María cuando ya había vuelto de Kaquel Huincul y estaba otra vez en la ciudad. Evidentemente, le resultaba atractiva la ficción de la correspondencia con la matrona, que enfatizaba su perfil de padre predicador, abocado a cumplir con su ministerio donde quiera que se encontrase, a la vez que satirizaba su figura. Su gusto por los libros es el motivo central de esa satirización, que se fundamenta en un tópico asociado con el apogeo de la novela y la aparición del tipo de lector enfebrecido por las historias ficcionales que llegaba hasta el extremo identificatorio de vivir como los héroes o las heroínas de los textos que leía (Littau 73-77). Ese modelo de apropiación del libro que apareció siguiendo el suceso de obras románticas tales como Pamela de Richardson y Julia o la nueva Eloísa de Rousseau no deja de enlazarse con la historia del manchego devenido caballero andante que Castañeda reivindicaba como libro de cabecera de sus atribulados periódicos-personajes. Detrás de los lectores arrebatados por la pasión novelesca y del héroe cervantino atiborrado de historias de caballería subyace una misma manera de afrontar los avatares vitales, esa actitud que Edward Said calificó de "textual" y que definió como el error de suponer que "los libros y los textos pueden ayudar a comprender el desorden impredecible y problemático en el que los seres humanos viven" (122). En la voluntad del Despertador y el Suplementista de revisar una a una las historias antes de partir al exilio ¿no anidaba esa creencia en el valor práctico de la palabra recogida en los libros? Lo notable es que los personajes de Castañeda hayan colmado su expectativa lectora echando mano de una historia en la que esa clase de relación con los libros era crudamente ridiculizada.

En el vínculo pecaminoso que Doña María le atribuye al cura con los materiales impresos, se diluía el componente instructivo que estaba presente en la práctica de la lectura en voz alta dirigida a las mujeres de las Conchas, a la vez que se magnificaban los trazos de la voracidad lectora que complementariamente se esbozaba en dicha audiencia femenina. En la representación que hace la redactora en su correspondencia, el libro es tierra fértil para el exceso y las relaciones ilegítimas; de ahí que surja la imagen del amancebamiento. Además, de los pe-

pedia metódica universal y la Enciclopedia de artes y ciencias (57). ¿Sería algunas de esas enciclopedias las que reclamaba el fraile? 
queños volúmenes del atadito que alimentaban la "leyenda" con las concheras se pasa a los "cientos tantos" tomos en folio de la enciclopedia. Castañeda, ciertamente, no se refería a la monumental obra de Diderot y D’Alembert, libro emblemático de la Ilustración, cuyo elenco de autores el padre tildada despectivamente de "pseudósofos". En su segundo papel, el Desengañador gauchipolítico, se quejaba de los "mozuelos antiteocrátas que en el año 20 se han lanzado con la enciclopedia universal" (397), lo que dejaba en claro su valoración negativa del género, especie de arma sacrílega con pretensiones de suplir el orden de Dios.

No obstante, aunque la aspiración de completitud de las enciclopedias configuraba de por sí un reto a Dios, a su saber y a su orden eternos y universales (por algo Diderot se refirió a su empresa como "grand et maudit ouvrage"), en algún punto el deseo de Castañeda se justificaba. Pedía la enciclopedia más completa porque — aclarabaestaba en una "travesía” (283), esto es, en un desierto, espacio que en el imaginario decimonónico refería a los territorios solo habitados por indios. La lista de cosas que precisaba debía medirse sobre la base de ese gran espacio en blanco para la "civilización". Necesitaba cuadros, estampitas, libros para poblar de imágenes y palabras impresas esos lugares alejados y llevar adelante allí la tarea de la catequesis cristiana y de la instrucción. Los volúmenes grandes de la enciclopedia eran a medida de ese vasto espacio en el que el cura estaba confinado. En términos simbólicos, la extensión de esos volúmenes se medía en su capacidad de contener un mundo ordenado de manera alfabética, un tejido de palabras y definiciones que podía solaparse sobre el lugar inexplorado, donde faltaba justamente la huella de la civilización (blanca y europea) y el nombre de las cosas.

\section{Caleidoscopio de lecturas y lectores (a modo de conclusión)}

En las escenas de lectura imaginadas por Castañeda, se representan distintas formas de apropiación lectora en cuyo desarrollo se mezclan de manera poco discernible trazos novedosos con otros que no lo son tanto. En la primera de ellas, los libros antiguos se acoplan con una manera de leer tradicional y de ese encuentro no sale nada provechoso. La desilusión de los personajes del fraile, que "recorren una a una 
las historias" sin hallar nada valioso, construye la imagen paradojal de una lectura que es, pero a la vez no es. Esa imagen, que es puramente negativa, tiene un poder desacralizante enorme: si podemos suponer que el libro sagrado del catolicismo estaba entre las historias indagadas por el Despertador y el Suplementista, hay que reparar en el hecho de que los personajes no encontraron nada en la Biblia. Agrego que no encontraron nada "de utilidad", puesto que ahí residía el meollo del tipo de lectura que, en los nuevos y turbulentos tiempos que corrían, no llegaba a cuajar: leer siempre los mismos libros con la certeza de que en ellos se encontrarán soluciones para los problemas vitales del presente.

Esta representación de la lectura frustrada permite indagar no ya en la figura de los nuevos lectores - objeto muy recurrido en los trabajos que abordan la lectura de las primeras décadas del siglo XIX ${ }^{16}$ - sino en los lectores tradicionales (varones cultos) y en sus estrategias de adaptación a las nuevas condiciones de legibilidad de los textos. En este caso, el contraste entre lectores cultos y populares o entre lectores y lectoras no tiene un lugar preponderante. Lo que se pone en cuestión es la práctica de la lectura intensiva. En otras palabras, la lectura repetida de libros siempre idénticos a sí mismos entraba en crisis, lo que insinuaba una ruptura entre el corpus de saberes tradicionales y las nuevas experiencias que deparaba el advenimiento de la modernidad.

Pero en el relato del Despertador hay un momento epifánico donde el acto de leer sí satisface a los lectores. Encabalgada entre la voluntad instructiva de inspiración religiosa y el ejercicio deseante, la tercera escena de lectura supone una relación de correspondencia entre el texto vocalizado, el lector-mediador y la audiencia femenina. Es la lectura en voz alta y comunitaria, cotidiana y no urbana que tiene lugar en el pueblo de las Conchas; lectura oída en la que no hay opinión ni pareceres de las oyentes, sino escucha embelesada. En el decir auspicioso de la anfitriona de los desterrados, las alegres imágenes que sirven para graficar esa escucha ("moscas a la miel y abejas a las flores" 1068), imágenes vegetales, voladoras y zumbonas, representan el acto de leer como el exacto reverso del itinerario inútil por las historias del pasado Me refiero específicamente a los trabajos de Batticuore, Martínez Gramuglia y Pas
que consigno en la bibliografía. 
en las que, desesperanzados, el Despertador y el Suplementista no encontraron nada. Son imágenes que enlazan con el principio de la historia y que, como si se tratara de una figura emblemática, insisten en la idea de una complementariedad perfecta y utópica entre el sujeto, la experiencia pasada, la representación de esa experiencia en libros, la lectura y los trances vitales del presente.

Esta tercera escena de lectura es, a su vez, parte de la vida de ficción que se inventan los personajes-periódicos de Castañeda al decidir imitar al Quijote y a Sancho Panza. En este punto, aparece el fraile como lector del gran clásico español (segunda escena de lectura). Lo curioso es que el Despertador y el Suplementista vivan la novela de Cervantes - o por lo menos un tramo de ella- y no les vaya tan mal. Así, la ecuación defendida por los moralistas desde el siglo XVIII en adelante, que ataba la sobreidentificación con un personaje novelesco a la caída en la locura, se quiebra. El fraile se comportaba como un lector desenfadado al ofrecer en su relato una pequeña reescritura del texto cervantino: en el caso del Depertador/Quijotiz (nombre que se pone el personaje para sellar su imitación del hidalgo de la Mancha) el apego excesivo a los libros, vicio que exponía con severidad risueña Doña María Retazos en las cartas con Castañeda, no deparaba calamidades; por el contrario, esa atracción funcionaba como fundamento aglutinante de la incipiente comunidad en la que los perseguidos encontraban un descanso para su errancia.

\section{Referencias bibliográficas}

Batticuore, Graciela. Lectoras del siglo XIX. Imaginarios y prácticas en la Argentina. Buenos Aires, Ampersand, 2017.

La mujer romántica. Lectoras, autoras y escritores en la Argentina: 1830-1870. Buenos Aires, Edhasa, 2005.

Bolter, David y Grusin, Richard. Remediation. Understanding New Media. Cambridge, Massachusetts Institute of Technology Press Edition, 1999.

Brunetti, Paulina, Matías Maggio Ramírez y María del Carmen Grillo. "Un puro vegetar. Representaciones de la lectura en el Semanario de Agricultura, Industria y Comercio (1802-1807)". Ensayos sobre la prensa. Primer concurso de investigación en periódicos argentinos en homenaje al Prof. Jorge B. Rivera. Dir. Paulina Brunetti y Matías Maggio Ramírez. Buenos Ai- 
res, Biblioteca Nacional, 2008. Recuperado de https://www. aacademica.org/maggioramirez/21.pdf

Castañeda, Francisco Paula de. Despertador Teofilantrópico MísticoPolítico. Buenos Aires, Imprenta de la Independencia/Imprenta Álvarez, 1820-1822.

. Desengañador Gauchi-Político, Federi-montonero, Chacuaco-orienta, Choti-protector y Puti-republicador de Todos los Hombres de Bien, que Viven y Mueren Descuidados en el Siglo Diez y Nueve de Nuestra Era Cristiana. Buenos Aires, Imprenta Álvarez, 1820-1822.

. Doña María Retazos de Varios Autores Trasladados Literalmente para Instrucción, y Desengaño de los Filósofos Incrédulos que al Descuido, y con Cuidado Nos Han Enfederado en el Año Veinte del Siglo Diez y Nueve de Nuestra Era Cristiana. Edición facsimilar. Buenos Aires, Taurus, 2001. Edición y estudio preliminar a cargo de Néstor T. Auza.

. Vete Portuguez, que Aquí No Es. Santa Fe, Imprenta de la Convención, 1828.

Cavia, Pedro Feliciano Saénz de. Cuatros Cosas o el Anti-fanático: el Amigo de la Ilustración, cuya Hija Primogénita es la Tolerancia: el Glosador de los Papeles Públicos Internos y Externos; y el Defensor del Crédito de Buenos Aires y Demás Provincias Hermanas. Buenos Aires, Imprenta de los Expósitos, 1821.

Chartier, Roger. El orden de los libros. Lectores, autores, bibliotecas en Europa entre los siglos XIV y XVIII. Trad. Viviana Ackerman. Barcelona, Gedisa, 1992.

Di Stefano, Roberto. "Lecturas políticas de la Biblia en la revolución rioplatense (1810-1835)". Anuario de la Historia de la Iglesia, no. 12, 2003, pp. 201-224.

Forace, Virginia. "Una breve aproximación al proyecto periodístico de Francisco de Paula Castañeda". XIX Jornadas Nacionales de Estética y de Historia del Teatro Marplatense: Los ecos de Eco. Mar del Plata, Universidad Nacional de Mar del Plata, 2016. 156-164.

- "El público diversificado en Doña María Retazos (18211822) de Francisco de Paula Castañeda". VIII Jornadas Internacionales de Filología y Lingüística y II de Crítica Genética "Las lenguas del archivo". La Plata, Universidad Nacional de La Plata, 2017. s/p. 
Herrejón Peredo, Carlos. Del sermón al discurso cívico: México, 17601834. Zamora/México D.F., El Colegio de Michoacán/El Colegio de México, 2003.

La Biblia Latinoamérica. Trad. Ramón Ricciardi y Bernardo Hurault. Madrid, Navarra, Ediciones Paulina/Editorial Verbo Divino, 1989.

Littau, Karin. Teorías de la lectura. Libros, cuerpos y bibliomanía. Trad. Elena Marengo. Buenos Aires, Manantial, 2008.

López Posa, Sagrario. "Florilegios, polyantheas, repertorios de sentencias y lugares comunes. Aproximación bibliográfica”. Criticó, no. 49, 1990, pp. 61-76.

Lyons, Martyn. Historia de la lectura y de la escritura en el mundo occidental. Buenos Aires, Ampersand, 2012.

Maggio Ramírez, Matías. “La mañana, amiga de las musas. Una hipótesis sobre la lectura matutina a principios del siglo XIX". Cruces y perspectivas de la cultura escrita en la Argentina: historia de la edición, el libro y la lectura. Dir. Alejandro Parada. Buenos Aires, Instituto de Investigaciones Bibliotecológicas, Facultad de Filosofía y Letras, Universidad de Buenos Aires, 2014, pp. 147-172.

Martínez Gramuglia, Pablo. "Nuevos textos, nuevos (y viejos) lectores: la representación del público en los periódicos de 1801 a 1810". Tres momentos de la cultura argentina: 1810-19102010. Comp. Graciela Batticuore y Sandra Gayol. Buenos Aires, Prometeo, 2012, pp. 25-40.

Martínez de Sousa, José. Diccionario de bibliología y ciencias afines. Madrid, Fundación Germán Sánchez Ruipérez, 1993.

Melot, Michel. Livro. Trad. Marisa Midori Deaecto y Valeria Guimaraes. San Pablo, Ateliê Editorial, 2012.

Parada, Alejandro. El dédalo y su ovillo. Ensayos sobre la palpitante cultura impresa en la Argentina. Buenos Aires, Instituto de Investigaciones Bibliotecológicas, Facultad de Filosofía y Letras, Universidad de Buenos Aires, 2012.

- El mundo del libro y de la lectura durante la época de Rivadavia. Una aproximación a través de La Gaceta Mercantil (1823-1828). Buenos Aires, Instituto de Investigaciones Bibliotecológicas, Facultad de Filosofía y Letras, Universidad de Buenos Aires, 1998. 
Pas, Hernán. 'La lectura de los que nada leen'. Prensa periódica y lectura en el siglo XIX". Desde el Sur, vol. 9, no.1, 2017, pp. 125144.

. "Quienes leen. Algunas notas sobre prensa, lectura y consumo." Lecturas del siglo XIX. Prensa, edición, cultura literaria. Ed. Hernán Pas. Buenos Aires, Ediciones Katatay, 2018, 185210.

Roman, Claudia. "De la sátira impresa a la prensa satírica. Hojas sueltas y periódicas en la configuración de un imaginario político para el Río de la Plata (1779-1834)". Estudios, vol. 18, no. 36, 2010, pp. 324-349.

. "Introducción". La prensa de Francisco de Paula Castañeda. Sueños de un reverendo lector (1820-1829). Ed. Claudia Roman. La Plata, Biblioteca Orbis Tertius, 2014a, pp. 5-25.

. "La prensa en red: los periódicos de Francisco de Paula Castañeda". Tramas impresas. Publicaciones periódicas argentinas (XIX-XX). Coords. Verónica Delgado, Alejandra Mailhe y Geraldine Rogers. La Plata, Facultad de Humanidades y Ciencias de la Educación, Universidad Nacional de La Plata, 2014b, pp. 47-63.

Said, Edward. Orientalismo. Trad. María Luisa Fuentes. Madrid, Libertarias, 1990.

Saldías, Adolfo. Vida y escritos del P. Castañeda. Buenos Aires, Arnaldo Moen y Hermano, 1907.

Schvartzman, Julio. Letras gauchas. Buenos Aires, Eterna Cadencia, 2013.

Ternavasio, Marcela. Historia de la Argentina 1806-1852. Buenos Aires, Siglo XXI, 2009.

Zinny, Antonio. Efemeridografía argirometropolitana hasta la caída de Rosas. Buenos Aires, Imprenta del Plata, 1869. 